\title{
agricultural history
}

FORTHCOMING ARTICLES:

The Land Market on the Wisconsin Frontier: An Examination of Land Ownership Processes in Turtle and LaPrairie Townships, 1839-1890 Sean Hartnett

Allotment Policy in an Incongruous Legal System: The Yakima Indian Nation, as a Case Study Barbara Leibhardt

Romantic Agrarianism in Twentieth-Century America David Danbom

Land Monopoly in Nineteenth-Century California Donald Pisani

Moving Truck Crops to Market: The Southem Transportation System and the Beginnings of Southern Truck Farming James McCorkle. Jr.

Creation of a Plantation System in the Arkansas Delta in the Twentieth Century Jeannie M. Whayne

Promoting a New South: Immigration, Racism, and "Alabama on Wheels" Katharine Pruett and John D. Fair

'Farmers Control': The 1908 Tobacco Strike in Central Kentucky Tracy Campbell

Subscriptions: $\$ 25.00$ for individuals: $\$ 47.00$ for institutions: $\$ 15.00$ for students. (Add $\$ 6.00$ postage for foreign orders.)

University of California Press

2120 Berkeley Way, Berkeley, CA 94720

Editor: Morton Rothstein,

Agricultural History Center University of California, Davis, CA 95616 


\section{Samuel Bronfman}

The Life and Times

of Seagram's Mr. Sam

MICHAEL R. MARRUS

"Samuel Bronfman (1891-1971), famed head of the Canadian Seagram Whiskey Corporation, made a rags-to-riches ascent from a poor Russian immigrant child to a millionaire businessman and influential Canadian Jewish leader.

University of Toronto history professor Marrus, who had access to both family and Seagram archives, recounts Bronfman's story with objectivity about his negative character traits and compassion for his battles against anti-Semitism. Authoritarian, hot-tempered and abrasive, 'Mr. Sam' skated close to the edge of illegality when he (legitimately) produced liquor in Canada that was destined for sale in Prohibition-bound America, although the author denies any connection to organized crime. Marketing skills and economic foresight brought Bronfman success in founding an empire and gave his family a life of luxury and prominence ... A vivid portrait of a controversial corporate giant." -Publishers Weekly

"Bronfman was one of the smartest big businessmen in mid-century North America, close to being the Henry Ford of his industry, obsessed with the quality and reputation of the product ... Marrus's book is the definitive biography of one of Canada's most colourful and most interesting high-achievers."

-Report on Business Magazine

Brandeis University Press

551 pages. 22 illus. $\$ 35.00$

\section{Cargill}

Trading the World's Grain WAYNE G. BROEHL, JR.

A leading business historian offers the first full-scale history of Cargill and its rise to international leadership among the "big five" grain traders.

"This is by far the most important historical evaluation of the only U.S.-created global grain company in the history of our nation. Wayne Broehl's descriptions and analysis reveal not only the history of an outstanding company and family but provide us insights into the commercialization of the national and global food system. This should be required reading for anyone interested in the development of institutions, leaders, and critical events that help shape the world's food network. It is a once in a lifetime type of study."

-Ray A. Goldberg

"A remarkably frank discussion of the inner workings and tensions of what has become one of the world's largest private corporations. It shows how a particular management style and corporate culture has been developed over time, but with quite notable continuity. The data on earnings, asset values, and sales reveal much that will be of great interest. It is a well-told story of how a rather modest grain company at the turn of the century became a sophisticated multinational company with continuing emphasis on agricultural products." - D. Gale Johnson

\section{New England}

University Press of New England • Hanover, NH 03755-2159 • 800-421-1561 


\title{
GUIDELINES FOR CONTRIBUTORS
}

\author{
General Information \\ Manuscripts are considered for publication on the understanding that they are not concurrently \\ under consideration elsewhere and that the material-in substance as well as form-has not been \\ previously published.
}

Three copies of the manuscript should be submitted.

Authors should identify themselves only on a separate title page that provides name, mailing address, and telephone number. Authors must also remember not to identify themselves in the body of the manuscript; specifically, references to their own work in the text should be in the third person, and citations should be written without possessive pronouns-not "See my. . . ."

Each article should be accompanied by a precis of 75-100 words outlining the main point(s) of the paper and placing the article in context. Subheads should be used to divide the manuscript into three or four sections (or more, depending on length).

We do not have an upper or lower page limit, but articles usually run between 25 and 60 typescript pages, including notes and other material.

Articles must contain notes in the humanities style, not references as in the social sciences.

We are always eager to publish illustrations, but authors should not include originals of illustrative materials at the time of submission; photocopies of such material may be included.

Authors of accepted manuscripts will receive two copies of the issue in which the article appears and twenty-five free offprints.

\section{Manuscript Propantion}

ALL material-including extracted quotations and notes-must be double-spaced. Legible photocopies or word-processed originals may be submitted. Use of dot-matrix printers is discouraged. Notes should be numbered consecutively and citations should be placed at the and of the text. Do not place footnotes at the bottom of the page (see word-processing instructions).

Each table or figure should ocupy a separate page and should be numbered (in arabic numerals) and grouped together between the text and the notes. The position of these items should be indicated in the text (as, "see Table 3"), but they should not be mingled with the text and no extra space should be left for them there. Each table and figure must be accompanied by a complete source.

We use the 13th edition of The Chicago Manual of Style (1982) and spell and hyphenate words according to Webster's Ninth New Collegiate Dictionary.

The journal encourages authors to use gender-neutral prose in all cases where it is not anachronistic to do so; male nouns and pronouns should not be used to refer to people of both sexes.

We use the day-month-vear form for dates, as 11 February 1990.

Double quotation marks should be used for journal titles and direct quotation; single quotation marks are used for quoted material inside quotations.

Sample Citation Forms:

Book: Alfred D. Chandler, Jr., The Visible Hand: The Managerial Rovolution in American Business (Cambridge, Mass., 1977), 321-22.

Journal: Charles Cheape, "Not Politicians but Sound Businessmen: Norton Company and the Third Reich," Business History Review 62 (Autumn 1988): 444-66.

Note that we do not include the publisher in book citations. We do not use loc. cit., op. cit., or idem., but ibid. (not italicized) may be used.

\section{Word-Processing Guidelines}

The journal can accept disks of all standard sizes and densities, but they must be formatted in MS-DOS; we cannot use Apple or MacIntosh software. WordPerfect is directly compatible, but we may be able to accept your document if it can be converted into an ASCII file.

Potential contributors should submit hard copy, not diskettes, initially, but it will save considerable work for all parties in the event of acceptance if authors working on PCs follow a few rules from the beginning:

In general, use as fow formatting commands as possible.

Do not justify or half-justify the right-hand margin.

Do not hyphenate words at the end of lines.

Do not use hard returns except for new paragraphs or required page ends except as absolutely necessary (for example, to break between text and notes)

Do not use special fonts; underline material that is to be set in italics.

Most important, do not use the word processor's automatic footnote functions: do not embed notes in the text. Notes should be keyed in at the end of the text (after any tables) or as a separate file. 


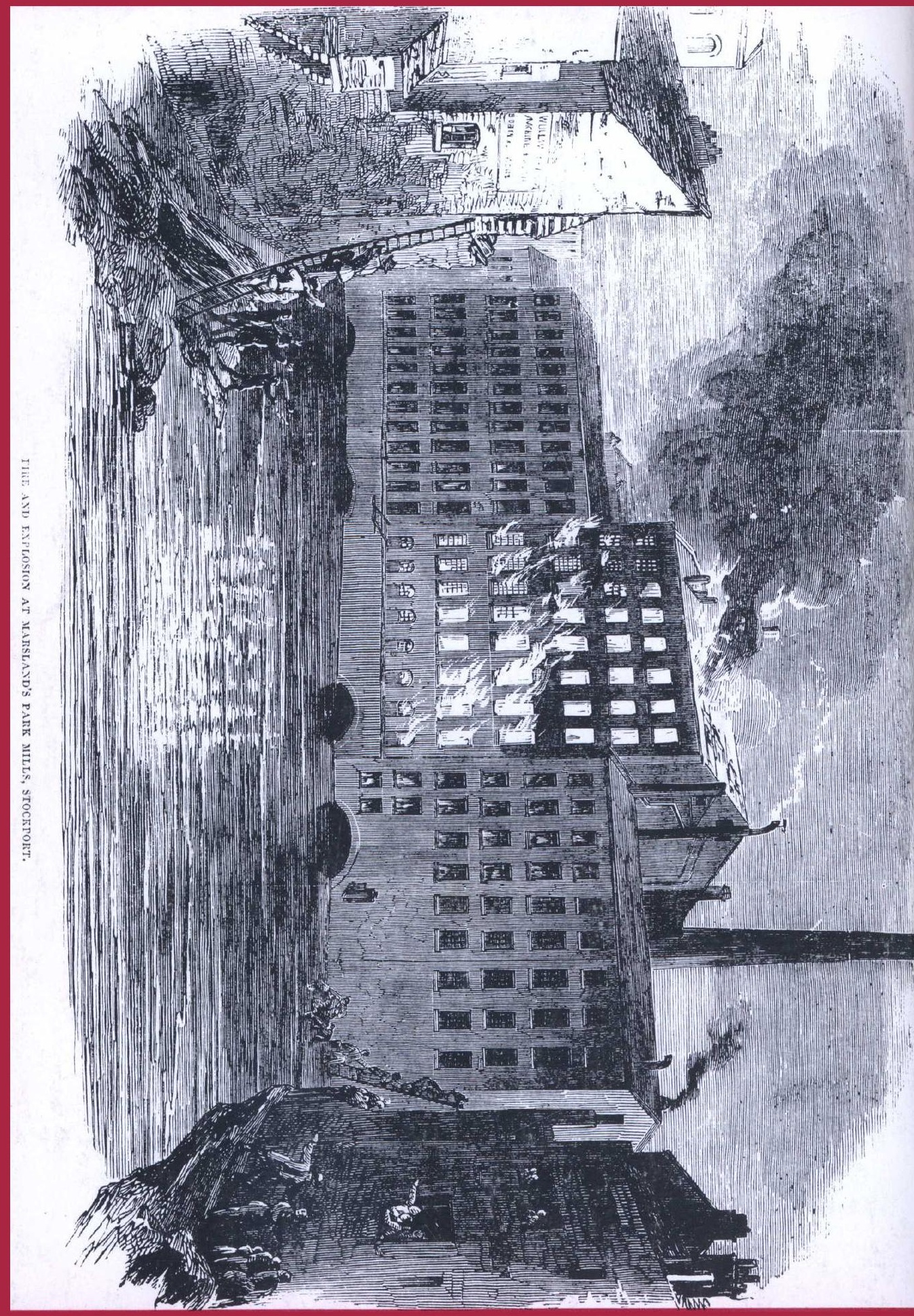

